DOI 10.37882/2223-2974.2021.01.17

\title{
СРАВНИТЕЛЬНЫЙ АНАЛИЗ МОДЕЛЕЙ ЭКОЛОГИЗАЦИИ РОЗНИЧНЫХ ТОРГОВЫХ ПРЕДПРИЯТИЙ НА ПРИМЕРЕ КОМПАНИЙ "Х5 RETAIL GROUP" И “ЛЕНTA"
}

\section{COMPARATIVE ANALYSIS OF ECOLOGIZATION MODELS OF RETAIL TRADE ENTERPRISES ON THE EXAMPLE OF "X5 RETAIL GROUP" AND "LENTA" \\ G. Mityashin \\ Yu. Katrashova \\ Yu. Mindlin}

Summary: This paper reviews ecologization models using the example of two major Russian retailers, X5 Retail Group and Lenta. The authors propose a scheme that reflects the 5 main stages of development of ecologization in the retail sector, identifying the transformation of the role of retail operators from reactive to proactive. The article contains a table describing the directions of ecologization: product ecologization, production ecologization and consumption ecologization, the complex development of which forms the strategy of ecologization of retail trade. The paper presents a case analysis of the greening models of "X5 Retail Group" and "Lenta", which have achieved significant success in the field of greening. Based on the results of the analysis, a petal chart is compiled that reflects the current achievements and weaknesses of the company's strategy. Based on this information, the authors conclude that the analyzed companies have chosen different vectors of activity in the field of greening: "X5" pays more attention to industrial greening, while "Lenta" focuses on greening the consumer environment. In conclusion, the author emphasizes the need to build a comprehensive strategy for greening retail trade enterprises, taking into account its 3 elements.

Keywords: retail, retail trade, retail chain, greening, lean consumption, waste processing.

\author{
Митяшин Глеб Юрьевич \\ ФГАОУ ВО «Санкт-Петербургский политехнический \\ университет Петра Великого» \\ gleb.mityashin@yandex.ru \\ Катрашова Юлия Валентиновна \\ ФГАОУ ВО «Санкт-Петербургский политехнический \\ университет Петра Великого» \\ ul.katrashova@gmail.com \\ Миндлин Юрий Борисович \\ К.э.н., доцент, ФГБОУ ВО «Московская государственная \\ академия ветеринарной медицины \\ и биотехнологии имени К.И. Скрябина» \\ mindliny@mail.ru
}

Аннотация: В данной работе производится обзор моделей эколоизации на примере двух крупных российских ритейлеров "X5 Retail Group" и "Лента". Авторы предлагают схему, отражающую 5 основных этапов развития экологизации в сфере розничной торговли, идентифицируя трансформацию роли розничных торговых операторов с реактивной на проактивную. Статья содержит таблицу, характеризующую направления экологизации: товарная экологизация, производственная экологизация и экологизация потребления, комплексное развитие которых формирует стратегию эклогизации розничной торговли. В работе представлен кейс-анализ моделей экологизации компаний "X5 Retail Group" и "Лента", которые достигли значительных успехов в области экологизации. По результатам анализа составляется лепестковая диаграмма, отражающая текущие достижения и слабые места стратегии компании. На ее основе авторы делают вывод о том, что анализируемые компании выбрали разные векторы деятельности в области экологизации: "Х5" уделяет большее внимание производственной экологизации, а "Лента" - на экологизации среды потребления. В заключении подчеркивается необходимость построения комплексной стратегии экологизации розничных торговых предприятий с учетом 3 ее элементов.

Ключевые слова: ритейл, розничная торговля, розничная торговая сеть, экологизация, бережливое потребление, переработка отходов.

\section{Введение}

B последние годы поле деятельности розничных торговых предприятий претерпело значительные изменения [1, 16]. Данные изменения вызваны трансформацией покупательских привычек, а именно стремлением к экономии времени и к бережливому потреблению $[2,8,12,21]$. Откликом ритейла является стремительное развитие интернет-торговли, которое довольно полно описано учеными $[3,5,6,11]$, и экологизация всех процессов, связанных с деятельностью магазинов. Отметим, что тенденция экологизации является более новой, чем развитие Интернет-торговли, поэтому получила меньшее освещение в научных статьях. Несмотря на то, что в работах российских авторов описаны некоторые процессы "зеленой экономики", их результаты лишь косвенно можно отнести к сфере розничной торговли $[4,13,17,20,27]$. В зарубежной литературе вопрос "озеленения" раскрыт более подробно, но большинство работ направлено на описание и анализ конкретных инструментов экологизации $[22,23,24,25,26]$, при этом вопросы, связанные с формированием комплексных стратегий экологизации, учеными не рассматриваются. 


\section{Шель работы}

Выполнить обзор моделей экологизации розничных торговых предприятий в контексте необходимости разработки комплексной стратегии экологизации.

\section{Основные результаты}

Розничные торговые сети в России являются крайне популярными и занимают значительную долю рынка (в некоторых регионах до 95\% всех розничных магазинов представлены торговыми сетями). Поэтому для поддержания конкурентоспособности им необходимо быстро реагировать на все актуальные тренды [18], одним из которых является экологизация. На схеме 1 отображены этапы процесса экологизации розничных торговых сетей, которые отечественные ритейлеры проходят в наши дни.

Схема 1.

Этапы экологизации розничных торговых предприятий.

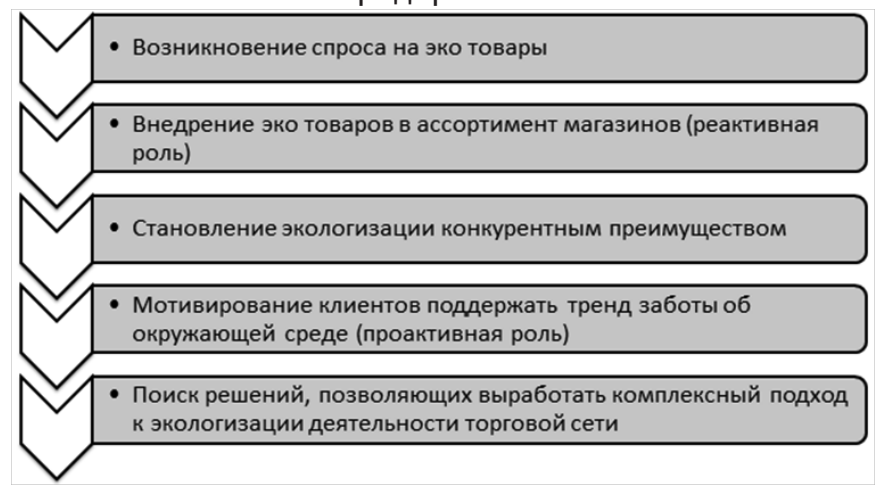

Схема 1 показывает, что изначально экологизация возникла как отклик на растущий спрос на эко товары и товары в перерабатываемой или многоразовой упаковке. Действия ритейлера для удовлетворения растущего спроса на данные товары путем внедрения их в ассортиментный перечень можно охарактеризовать как реактивные.

Отметим, что учет потребности клиента в потреблении боле экологичных товаров означает, что ритейлерам недостаточно просто обеспечить покупателям возможность приобретения желаемых товаров - необходимо обеспечить соответствие этих товаров (и, шире, модели обслуживания в целом) изменившимся ценностям потребителей [7]. Иными словами, экологизация становится неценовым конкурентным преимуществом, а саму экологизацию можно рассматривать как частный случай социального маркетинга, когда компания делает упор на развитие некоммерческих элементов [9].

Затем идея бережливого потребления в сфере роз- ничной торговли продолжает набирать популярность, поэтому практика реализации эко товаров перестает быть новшеством и превращается в неотъемлемую часть ассортимента. Поэтому ритейлеры начинают разрабатывать новую модель потребления, основывающуюся на осознанном потреблении. То есть роль ритейлера при внедрении элементов экологизации изменяется с реактивной на проактивную (под реактивной ролью стоит понимать действия по удовлетворению запросов покупателей, а под проактивной - предложение им новой модели потребления, основывающейся на осознанном потреблении, или ее элементов). Для более быстрого и успешного перехода посетителей на экологичную модель поведения, ритейлеры могут предлагать им различные мотивирующие бонусы, к примеру, скидки за покупку в многоразовую тару или скидки на отдельные, более экологичные позиции.

В свою очередь, экологичная модель потребления базируется на комплексной стратегии экологизации розничного торгового предприятия, реализация которой возможна в случае развития трех направлений экологизации, которые представлены в таблице 1, составленной авторами.

Таблица 1.

Направления экологизации ритейла.

\begin{tabular}{|l|l|}
\hline \multicolumn{1}{|c|}{ Направление экологизации } & \multicolumn{1}{|c|}{ Характеристика } \\
\hline Товарная экологизация & $\begin{array}{l}\text { Расширение предложения экологич- } \\
\text { ных товаров, товаров для здорового } \\
\text { образа жизни, товаров в экологичной } \\
\text { (многоразовой или перерабатываемой } \\
\text { упаковке). }\end{array}$ \\
\hline Экологизация потребления & $\begin{array}{l}\text { Создание условий для минимизации } \\
\text { ущерба окружающей среды при } \\
\text { потреблении товаров магазина (и иных } \\
\text { товаров). }\end{array}$ \\
\hline $\begin{array}{l}\text { Производственная } \\
\text { экологизация }\end{array}$ & $\begin{array}{l}\text { Эклогизация процессов, не связанныхс } \\
\text { обслуживанием покупателей. }\end{array}$ \\
\hline
\end{tabular}

Завершающим этапом формирования экологичной среды в ритейле является разработка комплексной стратегии, учитывающей все три направления экологизации, представленных в таблице 1. Разработка подобной стратегии является длительным и трудоемким процессом, однако значительно укрепляет позиции компании на конкурентном рынке. Для установления наиболее целесообразных действий в области "озеленения" розничной торговли авторы считают целесообразным рассмотреть действия компании "X5 Retail Group" и "Лента", которые достигли значительного прогресса в области производственной экологизации и экологизации потребления за последние несколько лет, однако достигли этого результата разными путями. 


\section{X5 Retail Group}

Данная компания достигла особых успехов в области производственной экологизации за счет изменений в организации работы магазинов и работы с поставщиками.

- Главным достижением "X5 Retail Group" является отправка значительной части отходов, возникающих в ходе торговой деятельности, на переработку. В компании отмечают, что в некоторых магазинах данный показатель стремится к 100\%. В 2019 году X5 отдала на переработку более 590 млн. кг., из которых 370 млн. кг. - картон, полиэтилен и пластиковые коробки, а также более 22 млн. кг. палет [15].

- Компания также стремится снизить количество операционных отходов за счет организации оптимальных поставок. С этой целью "X5 Retail Group" применяет технологии Big Data для прогнозирования оптимального размера поставки и для адаптации ассортимента для каждого магазина в зависимости от потребностей покупателей. Значительную роль в снижении отходов играет увеличение частоты поставок, что снижает количество испорченного товара, и соблюдение всех необходимых условий при хранении и транспортировки груза [15].

- Компания пересматривает договоры с фирмамипартнерами и поставщиками, чтобы внести в них положения, закрепляющие необходимость многоразового использования палет, контейнеров, ящиков и прочих упаковок, связанных с поставкой товаров. К поставщикам, которые поставляют изделия, сделанные из пластика, предъявляется условие, что их товары должны быть частично или полностью произведены из переработанного сырья. Это позволило компании обеспечить все "Перекрестки" центрального федерального округа пакетами, содержащими 35\% переработанного пластика, а во всех обновленных “Пятерочках" используются покупательские корзины, изготовленные из вторичного сырья [15].

- Покупателя всем магазинов X5 Retail group предлагается использование бумажных пакетов и фасовочной бумаги для мяса, рыбы, хлебобулочных изделий [15].

- В ассортименте всех магазинов имеются многоразовые сумки для покупок, а некоторых и пакеты для взвешивания [15].

- В офисах компании установлены автоматы для переработки бумаги и контейнеры для раздельного сбора мусора [15].

\section{ヘента}

Компания "Лента", равно как и "X5 Retail group" обеспокоена вопросами осознанного потребления и сокращению отходов, поэтому активно развивает данное направление. На сегодняшний день, компания перерабатывает незначительную часть производственных отходов, но имеет в ассортименте многоразовые пакеты и предлагает покупателям покупку некоторых групп товаров в собственную тару. "Лента" сделала ставку на экологизацию мест обслуживания потребителей и офисов компании:

- Полный отказ от одноразовой пластиковой посуды и стаканов в офисах. Взамен них компания закупила для сотрудников многоразовую брендированную посуду [10, 14$]$.

- Установка пандоматов для сбора пластиковых бутылок и алюминиевых банок в магазинах [10, 14].

- Наличие в каждом магазине контейнера для сбора использованных батареек и небольших аккумуляторов $[10,14]$.

Отметим, что сбор отходов, не вырабатываемых непосредственно магазином, свидетельствует о заинтересованности компании в формировании осознанного потребления своих посетителей. Размещение контейнеров для сбора батареек и пандоматов для сбора использованных бутылок в магазинах "Ленте" является оправданным, так как данный ритейлер оперирует сравнительно большим количеством гипермаркетов, в которые покупатели приезжают, как правило, на собственных транспортных средствах, что обеспечивает возможность привезти с собой отходы, которые можно утилизировать рационально.

- Предоставление скидки на товары мясной, молочной и других групп с истекающим сроком годности. Данное решение применяется практически всеми розничными торговыми сетями и направлено на снижение отходов деятельности магазина.

\section{Обсужмение}

С целью анализа текущих достижений в области построения комплексной стратегии экологизации и для идентификации различных подходов к ее построению авторы предлагают диаграмму 1, составленную ими на основе экспертной оценки данных с официальных сайтов компаний "X5 Retail Group" и "Лента", сведенных в таблицу 2. 
Текущие достижения компаний “X5 Retail Group" и "Лента" в области экологизации

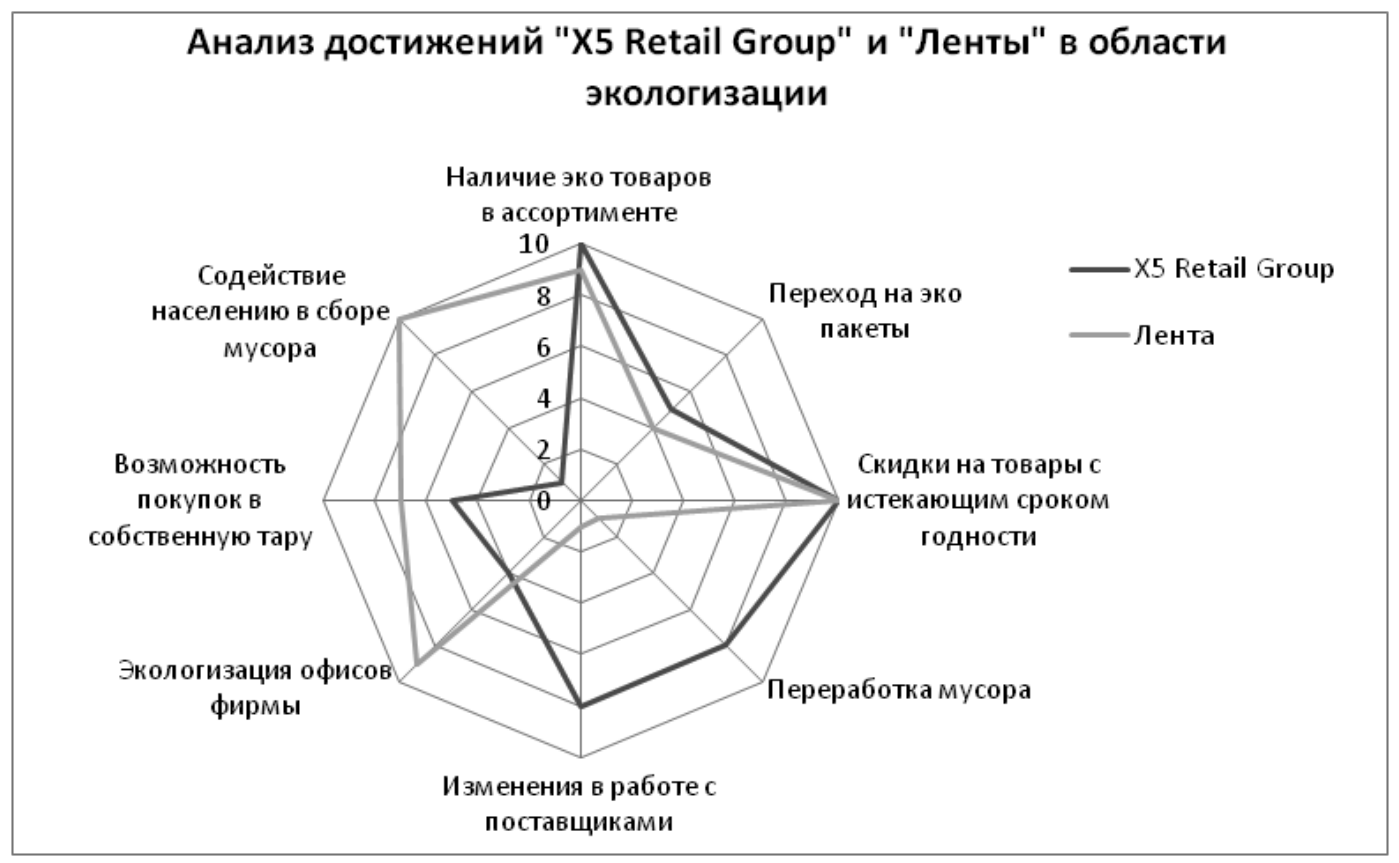

Таблица 2.

Текущие достижения компаний "X5 Retail Group" и "Лента" в области экологизации

\begin{tabular}{|c|c|c|c|}
\hline \multirow{2}{*}{ Направление экологизации } & \multirow{2}{*}{ Оцениваемый критерий } & \multicolumn{2}{|c|}{ Экспертная оценка авторов по 10ти бальной шкале } \\
\hline & & X5 Retail Group & Лента \\
\hline \multirow{3}{*}{ Товарная экологизация } & Наличие эко товаров в ассортименте & 10 & 9 \\
\hline & Переход на эко пакеты & 5 & 4 \\
\hline & Скидки на товары с истекающим сроком годности & 10 & 10 \\
\hline \multirow{3}{*}{ Производственная экологизация } & Переработка мусора & 8 & 1 \\
\hline & Изменения в работе с поставщиками & 8 & 1 \\
\hline & Экологизачия офисов фирмы & 4 & 9 \\
\hline \multirow{2}{*}{ Экологизация среды потребления } & Возможность покупок в собственную тару & 5 & 7 \\
\hline & Содействие населению в сборе мусора & 1 & 10 \\
\hline
\end{tabular}

Описание диаграммы:

1. Экспертная оценка выставлялась по 10 бальной шкале по каждому критерию, где "0" означает, что анализируемый элемент экологизации компанией не используется, "10" - анализируемый элемент экологизации реализован в полной мере.

2. Достижение отметки в 10 баллов по каждому критерию означает, что комплексная стратегия экологизации фирмы построена полностью и не нуждается в корректировки.

3. Площадь фигуры внутри линии соответствует текущему прогрессу компании, а оставшаяся площадь - тому, чего предстоит достичь.

4. На диаграмме представлены основные направления развития, их перечень может быть расширен.
Исходя из данных, представленных в таблице 2 и их наглядного отображения на диаграмме 1, можно сделать вывод о том, что на данный момент обе компании достаточно преуспели в сфере “озеленения" ритейла, однако нельзя сказать, что хотя бы одна из компаний приблизилась к созданию комплексной стратегии экологизации. Отметим, что анализируемые компании выделяют для себя разные векторы развития. Так, “Лента" делает большую ставку на экологизацию среды потребления, a X5 Retail Group на производственную экологизацию. B дальнейшем, компаниям стоит уделить большее внимание менее экологизированным показателям. Отметим, что важно избегать внедрения псевдоэкологичных решений (таких как бумажные пакеты), так как они являются исключительно маркетинговым инструментом и не приносят экологии никакой пользы. Федеральным и ре- 
гиональным торговым сетям и прочим розничным торговым предприятиям необходимо корректировать свою деятельность в соответствии с тенденций бережливого потребления, так как в современных условиях неценовые факторы становятся более значимыми, чем в период сверхпотребления [19]. Современное поколение проявляет большую сознательность при совершении покупок и, одновременно, является самым многочисленным кластером общества, поэтому формирование комплексной стратегии экологизации розничной торговой сети является гарантией ее долгосрочного устойчивого развития.

\section{Выводы}

Подводя итог, следует отметить, что тенденция экологизации ритейла является одной из самых быстро развивающихся и перспективных, что доказывает необходимость разработки комплексного плана мероприятий для создания комплексной стратегии экологизации. Как показывают результаты кейс-анализа, компании внедряют экологические решения на предприятия розничной торговли поэтапно, то есть, концентрируя внимание на одно из трех этапов экологизации: товарной, производ- ственной или экологизации среды потребления (таблица 1). Отметим, что крупные российские ритейлеры закончили работу по внедрению товарной экологизации и перешли к следующему этапу, где выбрали различные модели дальнейшего развития: "X5" сделала ставку на производственную экологизацию, а "Лента" - на экологизацию среды потребления. Различия в моделях экологизации объясняются разными текущими целями компаний: "Лента" стремится к созданию экологичной атмосферы в магазинах, популяризируя идею бережливого потребления среди покупателей, что оказывает положительное влияние на имидж компании и привлекает новых, озабоченных вопросами экологии клиентов. "X5 Retail Group" сфокусировалась на снижении отходов от деятельности магазинов, то есть оказывает влияние на поставщиков товаров для продажи и товаров для поддержания деятельности магазинов, лоббируя необходимость экологизации всех процессов, связанных с розничной торговлей. По мнению авторов, оба вектора деятельности являются важными, но достижение комплексной стратегии экологизации розничного торгового предприятия возможно лишь в случае учета обоих описанных факторов в деятельности предприятия.

\section{ЛИТЕРАТУРА}

1. Бахарев В.В., Митяшин Г.Ю. Тенденции развития ритейла в России // Экономический вектор. - 2020. - № 3 (22). - С. 54-60.

2. Бахарев В.В., Соловьева В.Г. Интернет торговля - инновационная форма развития торговли // В сборнике «Неделя науки СПбПУ»; материалы научной конференции с международным участием. СПбПу Петра Великого, Институт промышленного менеджмента, экономики и торговли. 2016 С. $232-235$.

3. Быковский Г.В. Управление отношениями с клиентами в российской интернет-коммерции: примеры компаний «Кей» и «Юлмарт» // Интернет-маркетинг. - 2017. - № 4. - С. 312-324.

4. Котляров И.Д. Сельский маркетинг: нетрадиционные модели сбыта продуктов питания // Маркетинг и маркетинговые исследования. - 2012. - № 6. C. 484-491.

5. Котляров И.Д. Тенденции эволюции электронной коммерции // Интернет-маркетинг. - 2012 - № 4 - С. $252-258$.

6. Котляров И.Д. Формы ведения предпринимательской деятельности в виртуальном пространстве: попытка классификации // Экономическая наука современной России. - 2011. - № 2. - С. 89-100.

7. Котляров И.Д. Четырехуровневая модель конкуренции // Маркетинг и маркетинговые исследования. - 2017. - № 4. - С. $244-254$.

8. Красюк И.А., Бахарев В.В., Медведева Ю.Ю. Инновационные решения в розничной торговле //Инновационная экономика: перспективы развития и совершенствования. 2017 № 3 (21). С. 32-38.

9. Куликова 0.М., Суворова С.Д. Влияние цифрового и социального маркетинга на поведение потребителей // Современная наука: актуальные проблемы теории и практики. Серия «Экономика и право». - 2020. - № 2. - С. 31-35.

10. Лента и экологизация // www.retail.ru [Электронный ресурс] URL: https://www.retail.ru/news/lenta-ustanovila-pervyy-pandomat-dlya-sbora-plastikovykhbutylok-v-leningradskoy-27-avgusta-2020-197148/ (дата обращения: 29.11.2020).

11. Максиянова Т.В. Место и роль интернет-коммерции в системе интрнет-эономики на современном этапе развития информационной (новой) экономики // Вопросы современной науки и практики. Университет им. В.И. Вернадского. - 2011. - № 3 (34). - С. 256-264.

12. Митяшин Г.Ю. Почему ритейлеры отказываются от гипермаркетов? // В сборнике: теоретические и прикладные вопросы экономики, управления и образования. Сборник статей Международной научно-практической конференции. - Пенза. - 2020г. - С. 258-261.

13. Митяшин Г.Ю. Тенденция экологизации в ритейле // В сборнике: Социально-экономические и гуманитарные науки. Сборник избранных статей по материалам Международной научной конференции. - 2020. - С. 74-75.

14. Официальный сайт Лента // lenta.com [Электронный ресурс] URL: https://lenta.com/o-kompanii/sotsialnaya-otvetstvennost/ (дата 0бращения: 29.11.2020).

15. Официальный сайт X5 Retail Group // www.x5.ru [Электронный ресурс] URL: https://www.X5.ru/ru/Pages/Sustainability/Waste.aspx (дата обращения: 29.11.2020).

16. Панкова Н.В., Богатырева С.В. Глобальный рынок розничной торговли: основные тренды, адаптационные технологии бизнеса // Управление экономическими системами: электронный научный журнал. - 2017. - № 4. - С. 53. 
17. Пирогова 0.Е., Емельянов А.Н. Экономическое обоснование создания системы утилизации отходов для предприятий сферы услуг // Международный научный журнал. - 2019. - № 3. - С. 28-33.

18. Суворова С.Д. Характеристика профиля современного потребителя // Инновационная экономика: перспективы развития и совершенствования. - 2019. - № 2. - С. 415-422.

19. Экологизация розничной торговли // new-retail.ru [Электронный ресурс] URL: https://new-retail.ru/marketing/trend_na_ekologiyu_pochemu_riteyleram_ pora_stanovitsya_zelyenymi4476/ (дата обращения: 29.11.2020).

20. Borkova E., Plotnikov V., Vatlina L., Shakhnovich R. (2019) Green Investments and Environmental Management: Russia's Experience. Vision 2020: Sustainable Economic Development and Application of Innovation Management, pp. 7394-7401.

21. Bozhuk S., Kozlova N., Krasnostavskaia N., Maslova T. Transformation of mechanism of sales and services promotion in digital environment // B сборнике: IOP Conference Series: Materials Science and Engineering. - 2019. - C. 12-14.

22. Chen T.B., Chai L.T. (2010) Attitude towards the environment and green products: Consumers' perspective. Management Science and Engineering, no. 4(2), pp. $27-39$.

23. Dabija D.C., Pop C.M. (2013) Green marketing - Factor of competitiveness in retailing. Environmental Engineering and Management Journal, no. 12(2), pp. 393-400.

24. Hallorana A., Clementc J., Kornumc N., Bucatariud C., Magid J. (2014) Addressing food waste reduction in Denmark. Food Policy, vol. 49, p. 1, pp. $294-301$.

25. Kumar P. (2014) Greening retail: an Indian experience. International Journal of Retail \& Distribution Management, vol. 42, no. 7, pp. 613-625.

26. Petljak K., Zulauf K., Štulec I., Seuring S. and Wagner R. (2018) Green supply chain management in food retailing: survey-based evidence in Croatia. Supply Chain Management, vol. 23, no. 1, pp. 1-15.

27. Vertakova Y.V., Plotnikov V.A. (2019) Assessment of the economic activity greening level and the green economy development directions. IOP Conf. Series: Earth and Environmental Science 392, pp. 01207.

( Митяшин Глеб Юрьевич (gleb.mityashin@yandex.ru), Катрашова Юлия Валентиновна (ul.katrashova@gmail.com), Миндлин Юрий Борисович (mindliny@mail.ru).

Журнал «Современная наука: актуальные проблемы теории и практики»

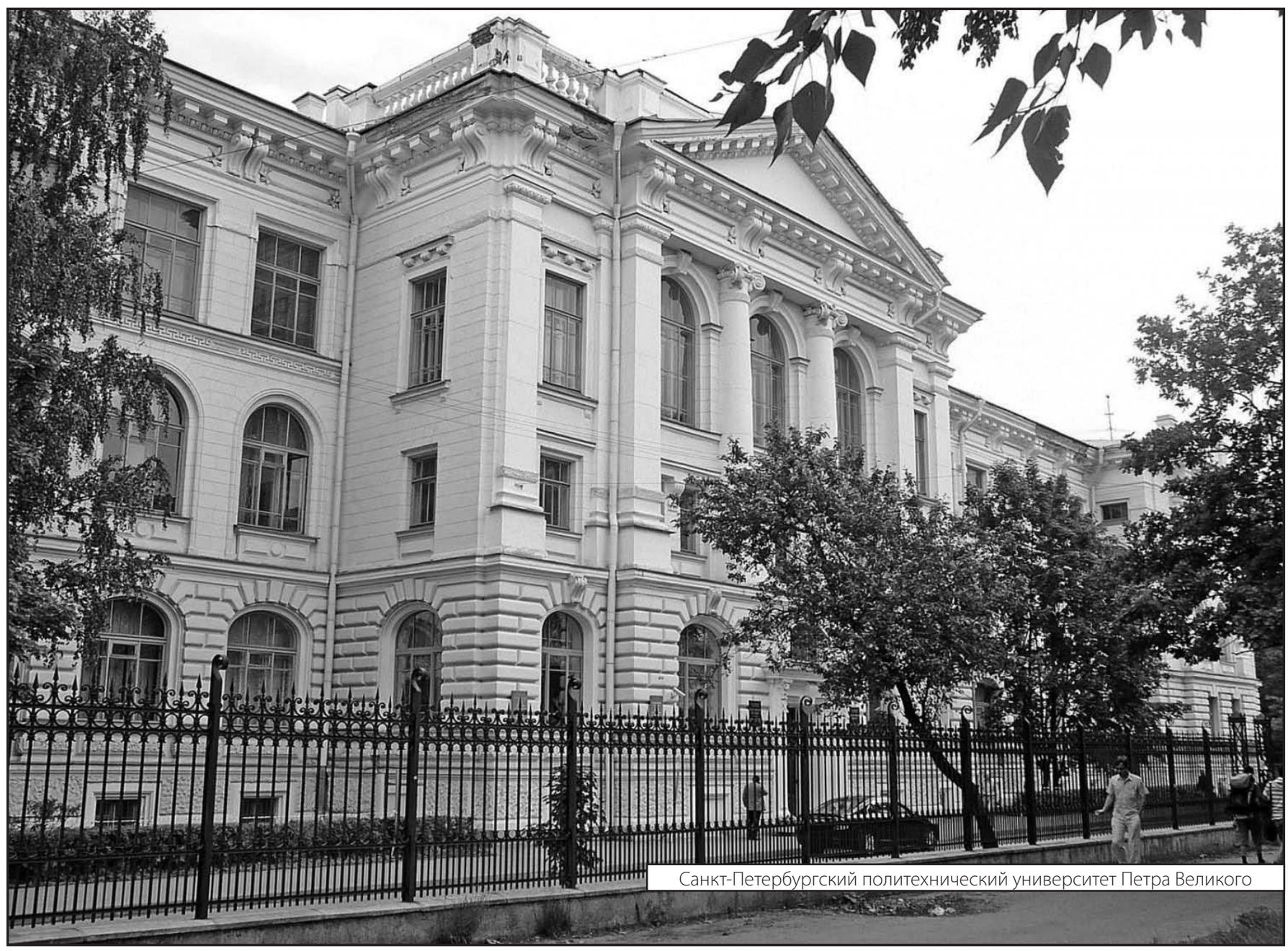

